\title{
Metabolic disparities of different oxidative stress-inducing conditions in HTR8/SVneo cells
}

\author{
JINGDONG CHEN ${ }^{1-4^{*}}$, TING-LI HAN ${ }^{1-3,5^{*}}$, XIAOBO ZHOU $^{1-3}$, \\ PHILIP BAKER ${ }^{2,5,6}$, YONG SHAO ${ }^{1-3}$ and HUAZHANG ${ }^{1-3}$ \\ ${ }^{1}$ Department of Obstetrics and Gynecology, The First Affiliated Hospital of Chongqing Medical University; \\ ${ }^{2}$ Chongqing Key Laboratory of Maternal and Fetal Medicine; ${ }^{3}$ Joint International Research Laboratory of \\ Reproduction and Development of Chinese Ministry of Education, Chongqing Medical University; \\ ${ }^{4}$ Chongqing Key Laboratory of Translational Medicine in Major Metabolic Diseases, The First Affiliated Hospital of \\ Chongqing Medical University, Chongqing 400016, P.R. China; ${ }^{5}$ Liggins Institute, University of Auckland, \\ Auckland 1023, New Zealand; ${ }^{6}$ College of Medicine, Biological Sciences and \\ Psychology, University of Leicester, Leicester, LE1 9HN, UK
}

Received June 7, 2019; Accepted November 14, 2019

DOI: $10.3892 / \mathrm{mmr} .2019 .10861$

\begin{abstract}
Placental oxidative stress is present throughout the duration of pregnancy, but it is when oxidative stress exceeds the normal physiological level that complications can occur. Trophoblast cell lines are commonly utilized for oxidative stress research due to their distinct uniform cell population and easy-to-apply interventions. However, conflicting results are often reported when different oxidative stress cell models are used. In this study, the aim was to characterize the intracellular and extracellular metabolite profiles of different oxidative stress cell models commonly used in the research of pregnancy complications. HTR8/SVneo human trophoblast cell lines were treated with five different oxidative stress-inducing conditions: Hypoxia (1\% oxygen); hypoxia and reoxygenation; cobalt chloride $\left(\mathrm{CoCl}_{2} ; 300 \mu \mathrm{mol} / \mathrm{l}\right)$; sodium nitroprusside (SNP; $2.5 \mathrm{mmol} / \mathrm{l}$ ); and the serum of women with preeclampsia $(10 \% \mathrm{v} / \mathrm{v})$. Intracellular metabolites were extracted from cells and extracellular metabolites were collected from spent media for metabolomic analysis via gas chromatography-mass spectrometry. The results demonstrated that there were distinct differences in the intracellular and extracellular metabolome between the different cell models. Meanwhile, treatments with exogenous drugs, such as $\mathrm{CoCl}_{2}$
\end{abstract}

Correspondence to: Professor Hua Zhang or Professor Yong Shao, Department of Obstetrics and Gynecology, The First Affiliated Hospital of Chongqing Medical University, 1 Youyi Road, Yuzhong, Chongqing 400016, P.R. China

E-mail: zh2844@gmail.com

E-mail: cqshaoyong@163.com

${ }^{*}$ Contributed equally

Key words: oxidative stress, metabolomics, hypoxia, cobalt chloride, sodium nitroprusside, preeclampsia and SNP, resulted in more similar metabolite profiles. These disparities between the different oxidative stress cell models will have implications for the applications of these results, and highlight the need for the standardization of oxidative stress cell models in obstetric research.

\section{Introduction}

Oxidative stress describes cellular damage caused by reactive oxygen/nitrogen species (ROS/RNS), combined with a biological inability to eliminate the oxidants or repair the consequent damage $(1,2)$. During the early stage of pregnancy, extravillous cytotrophoblast cells occupy the uterine spiral arterioles and create a low-oxygen environment (3). Thus, the placenta and embryo experience hypoxia-induced oxidative stress as part of the normal physiological process during early pregnancy (4-6). However, excessive elevated oxidative stress leads to complications such as preeclampsia (PE), spontaneous abortion and intrauterine growth restriction (7-9). Ethical considerations restrict the induction of oxidative stress directly onto the human embryo, so knowledge concerning the consequences of excessive oxidative stress during pregnancy has been solely acquired using cell and animal models (10). There are five main oxidative stress cell models used to investigate pregnancy complications (11-15). Firstly, there is hypoxia or low partial pressure of oxygen $\left(<5 \% \mathrm{O}_{2}\right)(13,16,17)$. Researchers usually culture cells in $1-2 \% \mathrm{O}_{2}$ for $12-72 \mathrm{~h}$ as a hypoxic condition to induce oxidative stress $(13,16,17)$. Hypoxia is perceived as the oxidative stress model for pregnancy complications because trophoblast invasion and/or vascular remodeling are compromised (18). The persistent placental ischemia results in elevated ROS production and provokes oxidative stress in the placenta (19). Conversely, hypoxia and reoxygenation (HR) mimics the oxidative stress induced by ischemia and reperfusion injury (14). Researchers commonly cultivate cells in a low partial pressure of oxygen (1-2\%) for $4-8 \mathrm{~h}$ and subsequently enhance the oxygen concentration to $20 \%$ to induce oxida- 
tive stress $(20,21)$. Alternatively, endogenous chemicals can be used to induce oxidative stress, cobalt chloride $\left(\mathrm{CoCl}_{2}\right)$ is known as a hypoxia mimetic agent. The hypoxia-inducible factor (HIF) activates the expression of genes that contain a hypoxia response element (HRE). The $\alpha$-subunits of the HIF transcription factors are degraded during normoxia and stabilized under hypoxic conditions (22). The cobalt prevents the degradation of HIF-1 $\alpha$ and mimics the HIF-HRE cascade-induced hypoxia (15). Another oxidative stressor, sodium nitroprusside (SNP) is a nitric oxide (NO) donor and induces a state of oxidative stress via the generation of ROS and RNS (5,23-25). Researchers often treat villi explants or cells with various concentrations of SNP to induce oxidative stress $(11,26,27)$. Finally, serum from patients with PE can be used; it is a common practice that researchers create PE-like cell models via the addition of PE serum/plasma into cell cultures $(12,28-31)$. This method mimics the second stage of the two-stage model of PE, which is often associated with oxidative stress (32).

There are studies that have attempted to apply the knowledge gained from these oxidative stress cell models to develop new therapeutic interventions for pregnancy complications $(33,34)$. For instance, in vitro studies using oxidative stress cell models have suggested that heparin may improve the uterine environment for successful implantation by preventing apoptosis caused by oxidative stress and modulating the decidual process (33). Furthermore, the antioxidant and cytoprotective mechanisms of aspirin have been observed in a hydrogen peroxide-mediated oxidative stress cell model, which may aid the understanding of the role of aspirin in reducing the risks of preterm birth, PE and fetal growth restriction (34). However, there are no published studies that have evaluated the different types of oxidative stress cell model used in pregnancy research. In this study, the aim was to investigate the metabolite profiles of a trophoblast cell line (HRT-8/SVneo) under five different models of oxidative stress using gas chromatography-mass spectrometry (GC-MS)-based metabolomic analysis. Identification of the metabolic similarities and discordances among the cell models will further the understanding of the mechanisms of oxidative stress and may have useful therapeutic implications for pregnancy complications.

\section{Materials and methods}

$P E$ serum. All serum samples ( $\mathrm{n}=6$; age range, 26-34 years) from participants with $\mathrm{PE}$ were collected from the Complex Lipids in Mothers and Babies study that was conducted at The First Affiliated Hospital of Chongqing Medical University in China between September 2015 and June 2017 (35). A total of $3 \mathrm{ml}$ of peripheral blood was collected from patients with PE, transferred into coagulation-promoting tubes and centrifuged twice at $2,400 \mathrm{xg}$ for $10 \mathrm{~min}$ at $4^{\circ} \mathrm{C}$. The supernatant serum was then transferred into cryotubes (Dakewe Biotech Co., Ltd.) and stored at $-80^{\circ} \mathrm{C}$ in a freezer. All participants at enrollment signed written informed consent and this study was approved by the Ethics Committee of Chongqing Medical University (policy no. 2014034).

Culturing HTR8/SVneocells. The immortalized human trophoblast cell line HTR8/SVneo was kindly donated by Dr Charles
Graham (Queen's University, Kingston, Canada) (36). The cells were cultured in RPMI-1640 medium (Gibco; Thermo Fisher Scientific, Inc.) supplemented with 10\% FBS (Gibco; Thermo Fisher Scientific, Inc.), penicillin $(100 \mathrm{U} / \mathrm{ml})$, and streptomycin $(0.1 \mathrm{mg} / \mathrm{ml})$ in $5 \% \mathrm{CO}_{2}$ at $37^{\circ} \mathrm{C}$. The cells were passaged at a ratio of 1:4 every 4 days.

Cytotoxicity assays of $\mathrm{CoCl}_{2}$ and SNP. To determine the most appropriate concentrations of $\mathrm{CoCl}_{2}$ and $\mathrm{SNP}$ for the oxidative cell stress model, the cytotoxicity of $\mathrm{CoCl}_{2}$ (Sigma-Aldrich; Merck KGaA) and SNP (Sigma-Aldrich; Merck KGaA) were assessed using Cell Counting Kit-8 (CCK-8) assays was used according to the manufacturer's protocols (Dojindo Molecular Technologies, Inc.). Briefly, HTR8/SVneo (1x10 4 cells/well) cells were seeded in a 96-well flat bottom plate and cultured overnight at $37^{\circ} \mathrm{C}$. Subsequently, cells were incubated with $100 \mu \mathrm{l}$ of RPMI-1640 medium with $\mathrm{CoCl}_{2}(0,100,200,300$, 400 and $500 \mu \mathrm{m})$ for $24 \mathrm{~h}$ or $\operatorname{SNP}(0,0.5,1,2,3$ and $4 \mathrm{mM})$ for $8 \mathrm{~h}$ at $37^{\circ} \mathrm{C}$. A total of five wells/group were tested at each concentration on the gradient. After $10 \mu \mathrm{l}$ of CCK- 8 solution was added to each well, cells were incubated at $37^{\circ} \mathrm{C}$ for $3 \mathrm{~h}$, and the absorbance was measured at $450 \mathrm{~nm}$, using a microplate reader.

Oxidative stress models. For subsequent experiments, the cells were seeded in complete medium in $10-\mathrm{cm}$ dishes at $5 \times 10^{5}$ cells/dish, under standard culture conditions overnight $\left(37^{\circ} \mathrm{C}\right.$ in a $5 \%$-humidified $\mathrm{CO}_{2}$ incubator). The cells were separated randomly into seven groups with six replicates per treatment. There were two control groups under normal levels of oxygenation $\left(20 \% \mathrm{O}_{2}, 5 \% \mathrm{CO}_{2}\right.$ and $\left.75 \% \mathrm{~N}_{2}\right)$; one group was prepared for $8 \mathrm{~h}$ (control for SNP) and the second was prepared for $24 \mathrm{~h}$ (control for hypoxia, $\mathrm{HR}, \mathrm{CoCl}_{2}$ and $\mathrm{PE}$ serum). A total of five oxidative stress groups were prepared: Hypoxia for $24 \mathrm{~h}\left(1 \% \mathrm{O}_{2}, 5 \% \mathrm{CO}_{2}\right.$ and $\left.94 \% \mathrm{~N}_{2}\right)$; hypoxia followed by reoxygenation for $12 \mathrm{~h} ; \mathrm{CoCl}_{2}(300 \mu \mathrm{mol} / \mathrm{l})$ under normal oxygenation for $24 \mathrm{~h}$; serum of patients with $\mathrm{PE}(10 \% \mathrm{v} / \mathrm{v})$ under normal oxygenation for $24 \mathrm{~h}$; and SNP $(2.5 \mathrm{mmol} / \mathrm{l})$ under normal oxygenation for $8 \mathrm{~h}$.

Extracellular metabolite collection from culture medium. After the oxidative stress conditions were established, $1.5 \mathrm{ml}$ of cell culture medium was transferred to a centrifuge tube and cell debris was removed by centrifugation at $4^{\circ} \mathrm{C}$ and $2,000 \mathrm{x} \mathrm{g}$ for $10 \mathrm{~min}$. The supernatants were isolated and $20 \mu \mathrm{l}$ of 2,3,3,3-d4-alanine (10 mM; Thermo Fisher Scientific, Inc.) internal standard was added. The blank media was treated exactly the same way without any cell components. The isolated supernatants were then concentrated by a Labconco CentriVap ${ }^{\circledR}$ SpeedVac concentrator (Labconco Corporation) for $4-5 \mathrm{~h}$ and stored at $-80^{\circ} \mathrm{C}$ prior to chemical derivatization.

Intracellular metabolite extraction from treated HTR8/SVneo cells. Treated HTR8/SVneo cells were washed with $10 \mathrm{ml}$ of PBS at $37^{\circ} \mathrm{C}$. Cellular metabolism was terminated by the addition of $15 \mathrm{ml}$ of liquid nitrogen into the cell culture dishes. After the evaporation of liquid nitrogen, $1.5 \mathrm{ml}$ of cold methanol-chloroform extraction solvent at $4^{\circ} \mathrm{C}$ (9:1 ratio with $20 \mu 1$ 2,3,3,3-d4-alanine; 10 mM; Thermo Fisher Scientific, Inc.) was added. Then, the cells were scraped with a cell lifter 
A

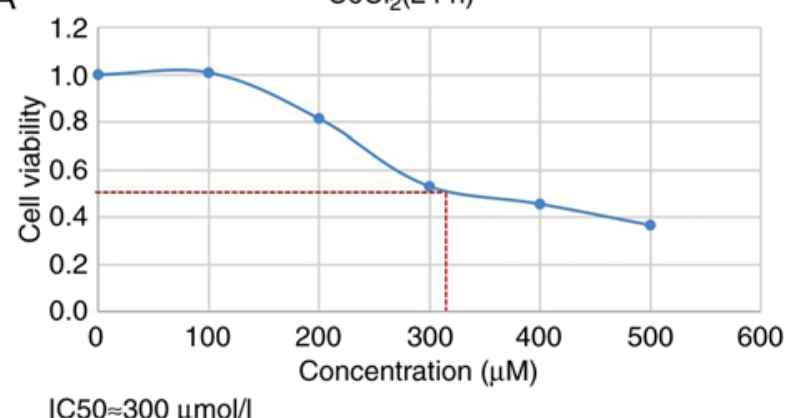

B

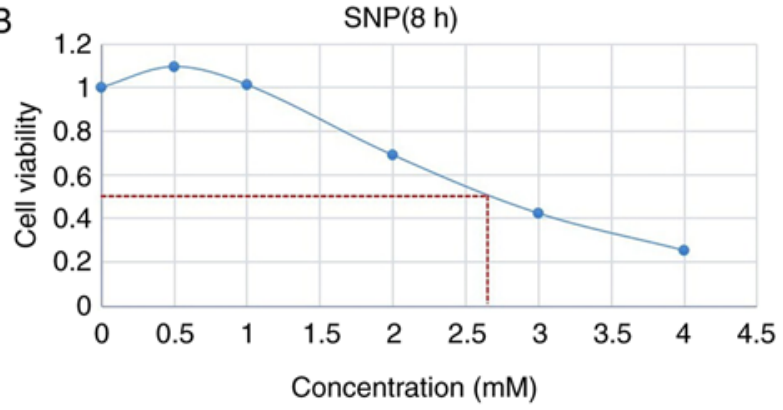

$I C 50 \approx 2.5 \mathrm{mmol} / \mathrm{l}$

Figure 1. Concentrations of $\mathrm{CoCl}_{2}$ and SNP treatments as determined using cell viability assays. HTR8/SVneo cells were treated with different concentrations of (A) $\mathrm{CoCl}_{2}$ for $24 \mathrm{~h}$ and (B) SNP for $8 \mathrm{~h}$. Percentages of viable cells were measured using the Cell Counting Kit- 8 assay. The viability of HTR8/SVneo cells was inhibited by $\mathrm{CoCl}_{2}$ and SNP in a dose-dependent manner, showing an IC50 of $300 \mu \mathrm{M}$ and $2.5 \mathrm{mM}$, respectively. $\mathrm{CoCl}_{2}$, cobalt chloride; SNP, sodium nitroprusside; IC50, inhibited concentration at which $50 \%$ of the cells were viable.

and transferred to a $1.5-\mathrm{ml}$ centrifuge tube. After vortexing for $30 \mathrm{sec}$, samples were centrifuged for $15 \mathrm{~min}$ at $4^{\circ} \mathrm{C}$ at 20,000 $\mathrm{xg}$, and the supernatant was isolated and dried using a Labconco CentriVap SpeedVac concentrator for 4-5 h.

Methylchloroformate (MCF) derivatization and GC-MS analysis. The dried pellets were resuspended in $200 \mu \mathrm{l}$ of sodium hydroxide $(1 \mathrm{~mol} / \mathrm{l})$ and then transferred into silanized glass tubes. The MCF derivatization was performed in accordance with the protocol published in Smart et al (37). The derivatives of the MCF metabolites were analyzed using an Agilent GC7890B system (Agilent Technologies, Inc.) coupled to a MSD5977A mass spectrometer (Agilent Technologies, Inc.) with the electron impact ionization set at $70 \mathrm{eV}$. The gas chromatograph used to separate the metabolites was a Zebron ZB-1701 Capillary GC column (30 mx250 $\mu \mathrm{m}$ id $\mathrm{x} 0.15 \mu \mathrm{m}$ with a $5 \mathrm{~m}$ guard column; Phenomenex); $1 \mu 1$ of derivatized sample was injected into the GC inlet that operated at $290^{\circ} \mathrm{C}$ in a split-less mode under $180 \mathrm{kPa}$ for $1 \mathrm{~min}$. Details of GC and MS parameters were also set up according to the methodology reported in Smart et al (37). Helium gas flow rate was constantly controlled at $1 \mathrm{ml} / \mathrm{min}$. The GC oven temperature was initiated at $45^{\circ} \mathrm{C}$ for $2 \mathrm{~min}$ and raised to $180^{\circ} \mathrm{C}$ at $9^{\circ} \mathrm{C} / \mathrm{min}$ for $5 \mathrm{~min}$. Subsequently, the oven temperature was raised at $40^{\circ} \mathrm{C} / \mathrm{min}$ to $220^{\circ} \mathrm{C}$ and held for $5 \mathrm{~min}$. The temperature was then increased again at $40^{\circ} \mathrm{C} / \mathrm{min}$ to $240^{\circ} \mathrm{C}$ and held for $11.5 \mathrm{~min}$. The last temperature increase was at $40^{\circ} \mathrm{C} / \mathrm{min}$ to

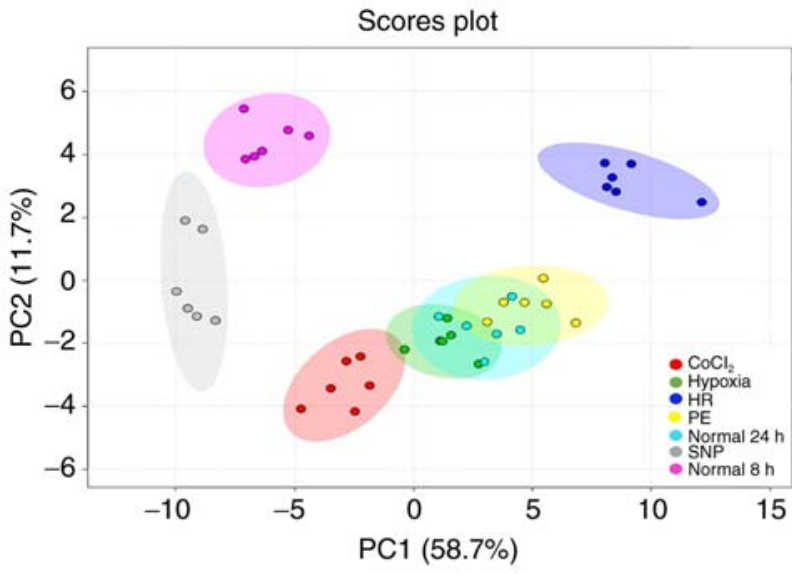

Figure 2. PC analysis plot of the metabolic profiles of HTR8/SVneo cells treated under seven different conditions. Samples with similar metabolite profiles appear closer together. Colored ellipses represent the $95 \%$ confidence intervals. $\mathrm{CoCl}_{2}$ group (red dots), hypoxia group (green dots), HR group (dark blue dots), normal $24 \mathrm{~h}$ group (bright blue dots), PE group (yellow dots), SNP group (grey dots) and normal $8 \mathrm{~h}$ group (purple dots). $\mathrm{CoCl}_{2}$, cobalt chloride; SNP, sodium nitroprusside; PE, preeclampsia; HR, hypoxia and reoxygenation; PC, principal component.

$280^{\circ} \mathrm{C}$ and held for $2 \mathrm{~min}$. The transfer interface between GC and MS was setup at $250^{\circ} \mathrm{C}$, the MS ion source at $250^{\circ} \mathrm{C}$ and the quadrupole at $130^{\circ} \mathrm{C}$.

Data mining and statistical analyses. Metabolite identification and chromatographic deconvolution were performed using AMDIS software (V2.1; National Institute of Standards and Technology). The MS1 metabolite identifications were achieved by comparing their fragmentation mass spectrum to the in-house MCF mass spectral library (built using chemical standards) (37) and associated retention time within a 1-min window. The relative concentration of identified metabolites was calculated using the in-house XCMS-based R script (V 3.8.1) (38) by identifying the most abundant fragment ion within an accurate retention time window. The metabolite concentrations were normalized by 2,3,3,3-d4-alanine and total protein level was used to correct for any dilution effect. The extracellular metabolites were determined by subtracting the levels of the corresponding metabolites detected in the control medium without any cellular components. Principal component analysis (PCA) was conducted via Metaboanalyst 3.0 package for R (39). Tukey's honest significant difference test was conducted to test for significant differences between the treatment and the control groups. A false discovery rate (Q-value) was used to account for multiple comparison testing. Both $\mathrm{P}<0.05$ and $\mathrm{Q}<0.05$ were regarded as statistically significant. Heatmap and line plots were illustrated via ggplot $2 \mathrm{R}$ packages (40).

\section{Results}

Cytotoxic effects of $\mathrm{CoCl}_{2}$ and SNP on cell viability. The viability of HTR8/SVneo cells was inhibited in a dose-dependent manner by $\mathrm{CoCl}_{2}$ (Fig. 1A) and SNP (Fig. 1B). The inhibited concentration (IC) of $\mathrm{CoCl}_{2}$ at which $~ 50 \%\left(\mathrm{IC}_{50}\right)$ of the cells were viable was $300 \mu \mathrm{m}$ (Fig. 1A), while the $\mathrm{IC}_{50}$ of SNP on HTR8/SVneo cells was $\sim 2.5 \mathrm{mM}$ (Fig. 1B). Therefore, 


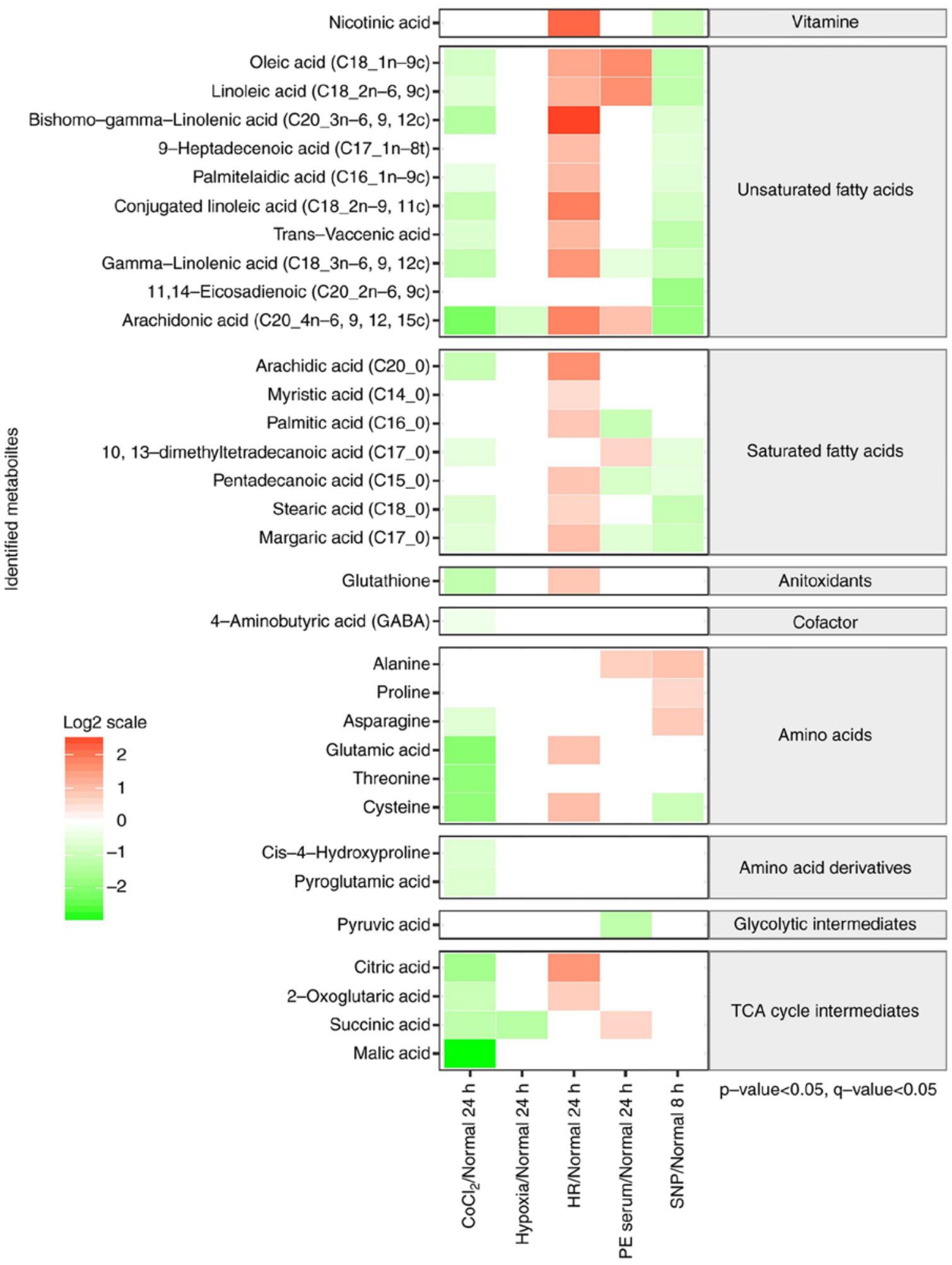

Figure 3. Heatmap demonstrating differences in the intracellular metabolome across five oxidative stress cell models, when compared to their corresponding control group. Relative levels of intracellular metabolites are shown by a $\log _{2}$ scale. Red colored squares show higher metabolite concentrations in the oxidative stress cell model groups than the control groups, whereas green colored squares indicate reduced metabolite concentrations in the oxidative stress cell model groups when compared to the control groups. Only the intracellular metabolites with $\mathrm{P}<0.05$ and $\mathrm{Q}<0.05$ (false discovery rate) are shown. $\mathrm{CoCl}_{2}$, cobalt chloride; HR, hypoxia and reoxygenation; PE, preeclampsia; SNP, sodium nitroprusside; TCA, tricarboxylic acid.

$300 \mu \mathrm{m}$ of $\mathrm{CoCl}_{2}$ and $2.5 \mathrm{mM} \mathrm{SNP}$ were chosen for this experiment.

Intracellular metabolite profiling of five oxidative stress cell models. The PCA scores plot (Fig. 2) of the intracellular metabolite profiles of the five models revealed a clear separation between the SNP group compared to the normal $8 \mathrm{~h}$ control group, as well as a distinct disparity between the $\mathrm{CoCl}_{2}$ and HR groups, when compared to the normal $24 \mathrm{~h}$ control group. Meanwhile, the hypoxia and PE group didn't show a 


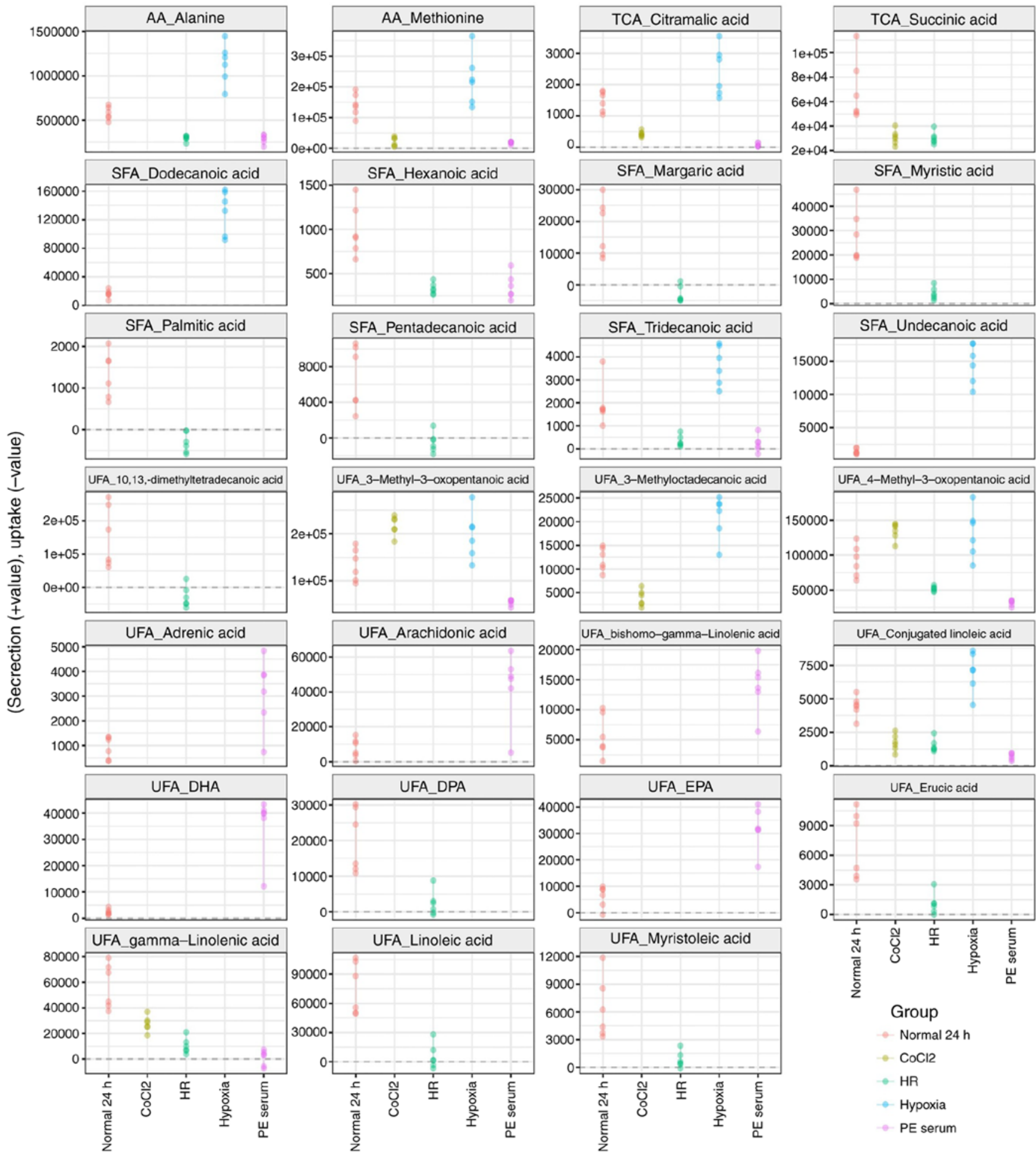

Figure 4. Relative levels of extracellular metabolites for HTR8/SVneo cells when cultured under $\mathrm{CoCl}_{2}, \mathrm{HR}$, hypoxia and PE serum conditions. The line $\mathrm{y}=0$ distinguishes secretion of metabolites into the medium (positive values) from consumption of metabolites from the medium (negative values). Only the metabolites for which there was a statistically significant $(\mathrm{P}<0.05)$ difference in concentrations between normal $24 \mathrm{~h}$ group and the treatment group were displayed AA, amino acid; TCA, tricarboxylic acid; SFA, saturated fatty acid; UFA, unsaturated fatty acid; $\mathrm{CoCl}_{2}$, cobalt chloride; HR, hypoxia and reoxygenation; PE, preeclampsia.

distinct disparity from the normal $24 \mathrm{~h}$ group. The first two principal components explained 58.7 and $11.7 \%$ of the variance in intracellular metabolites between all experimental groups. There were a total of 103 metabolites identified by the in-house mass spectral library, 33 of which were found to significantly differ between the five oxidative stress cell models and the corresponding normal control groups $(\mathrm{P}<0.05$ and $\mathrm{Q}<0.05$; Fig. 3). Levels of saturated and unsaturated intracellular fatty acids were lower in the models treated with $\mathrm{CoCl}_{2}$ and SNP. Lower levels of glutathione, four amino acids, two amino acid derivatives and all of the tricarboxylic acid (TCA) cycle intermediates were also observed in the $\mathrm{CoCl}_{2}$-treated cells. In 

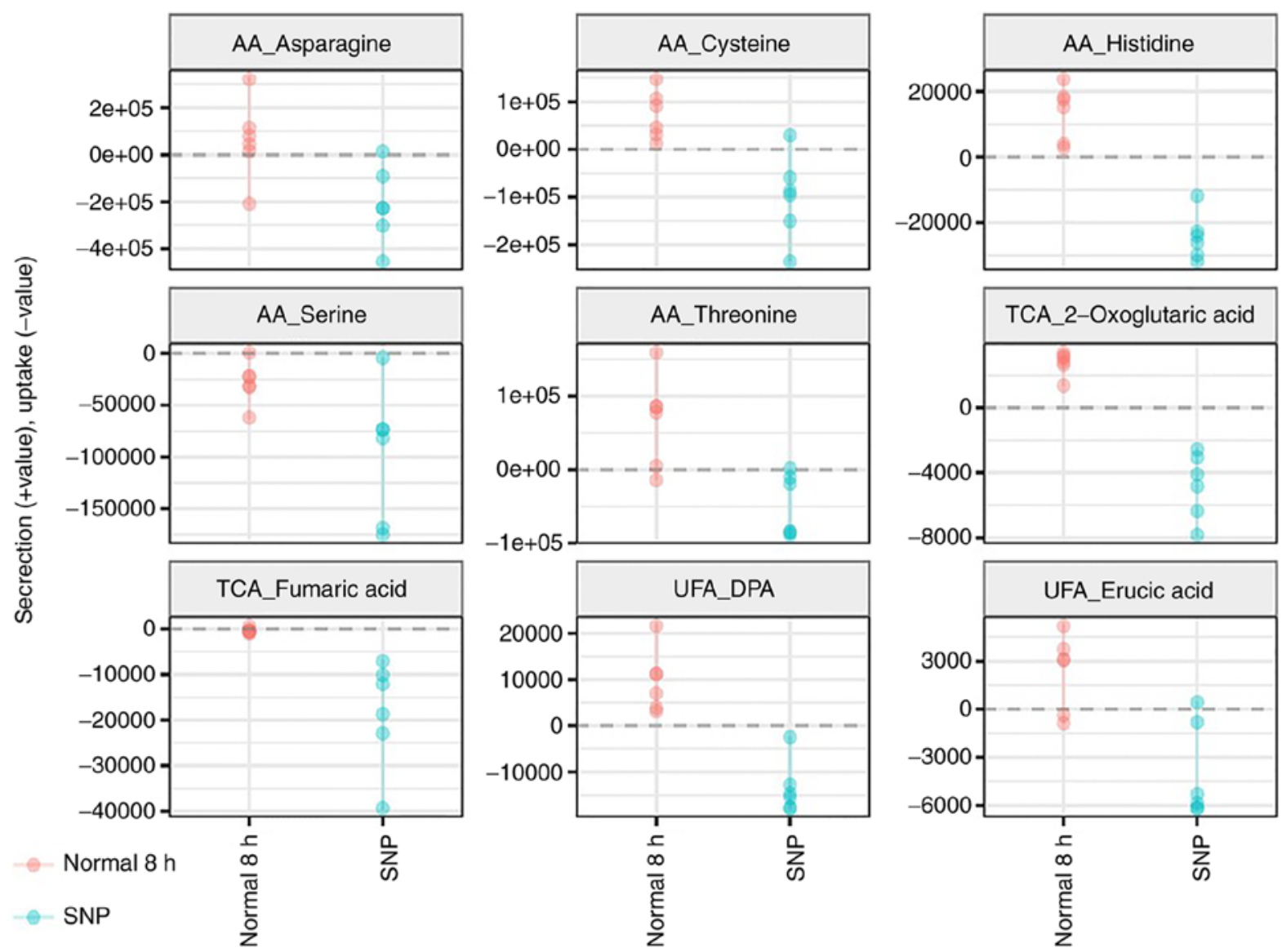

Figure 5. Relative levels of extracellular metabolites for HTR8/SVneo cells when cultured with SNP. The line $y=0$ distinguishes secretion of metabolites into the medium (positive values) from consumption of metabolites from the medium (negative values). Only the metabolites for which there was a statistically significant $(\mathrm{P}<0.05)$ difference in concentrations between normal $8 \mathrm{~h}$ group and the treatment group were displayed. AA, amino acid; TCA, tricarboxylic acid; UFA, unsaturated fatty acid; SNP, sodium nitroprusside.

contrast, nine unsaturated fatty acids, six saturated fatty acids, glutathione, two amino acids and two TCA cycle intermediates were found to be significantly elevated in the cells exposed to the HR treatment. Metabolite levels were altered in various ways when treated with PE serum (six metabolites increased and five decreased) and only two metabolites, arachidonic acid and succinic acid, were reduced in response to hypoxic conditions (Fig. 3). The overall intracellular metabolite profiles differed greatly between the five oxidative stress cell models.

Extracellular metabolite profiling of five oxidative stress cell models. A total of 174 metabolites were detected in the spent media of the HTR8/SVneo culture; 36 of the extracellular metabolites, including amino acids, unsaturated fatty acids, saturated fatty acids and TCA cycle intermediates, were significantly different $(\mathrm{P}<0.05$ and $\mathrm{Q}<0.05)$ compared with the normal and oxidative stress-treated groups (Figs. 4 and 5). A reduction in the secretion of metabolites, including one amino acid (methionine), two TCA cycle intermediates and two unsaturated fatty acids, was observed when the cells were treated with $\mathrm{CoCl}_{2}$. When grown in hypoxic conditions, most of the amino acids and unsaturated fatty acids were secreted into the spent media. In contrast, all the significant extracellular metabolites were found in lower levels following exposure to the HR conditions. In the case of PE serum, levels of the majority of the extracellular unsaturated fatty acids were significantly increased. Interestingly, all significant extracellular metabolites were absorbed from the culture medium when cells were treated with SNP (Fig. 5).

\section{Discussion}

The present study is the first, to our knowledge, to apply metabolomics to investigate the differences in the intracellular and extracellular metabolite profiles of oxidative stress cell models induced in vitro. Selecting an appropriate cell model of oxidative stress applicable to obstetric research is a challenging endeavor. One criterion that may be useful in future selections is how well the model resembles the metabolic etiology of the pregnancy complication under investigation. Large metabolic disparities were observed between the five different cell models investigated in the present study. This raises concerns that the use of different models of oxidative stress in prior studies may be responsible for the contradictory findings observed.

The HR cell model demonstrated accumulation of all intracellular metabolites and increased nutrient uptake. During hypoxia, the oxygen deficiency resulted in the downregulation of ATP production, and energy metabolism shifted towards gluconeogenesis and fatty acid oxidation. Anaerobic respiration converts glucose into lactate to sustain cellular viability (41). Nevertheless, anaerobic respiration is unable to 
meet the requirement of the aerobic cell, as a result the electron transport chain is damaged and intracellular $\mathrm{pH}$ levels are reduced (42). During the subsequent reoxygenation, ROS are generated through the incomplete reduction of oxygen by the damaged mitochondria (43). In order to protect against free radicals, cells may uptake more nutrients to feed into the TCA cycle for the generation of additional NADPH required to maintain glutathione levels $(43,44)$. The results of the present study suggested that HTR8/SVneo cells raise the levels of intracellular metabolites to protect from oxidative stress induced by hypoxia followed by reoxygenation.

Interestingly, both $\mathrm{CoCl}_{2}$ and SNP-treated cell models expressed the most similar metabolic profiles, in that all intracellular and extracellular metabolites were reduced following $\mathrm{CoCl}_{2}$ treatment, whereas all intracellular fatty acids were decreased following SNP treatment. It is commonly known that $\mathrm{CoCl}_{2}$ has the ability to stimulate an intracellular hypoxia-like condition by regulating the stability of HIF-1 $\alpha$, thus upregulating hypoxia-associated genes, reducing antioxidant enzymes and rapidly increasing levels of intracellular ROS (45). As a result, $\mathrm{CoCl}_{2}$ may lead to cytotoxicity and downregulate the global cellular metabolism, attenuating the biosynthesis of intracellular metabolites and compromising extracellular excretion. On the other hand, SNP is readily degraded into NO, which in turn acts to induce oxidative degradation of unsaturated fatty acids, thus resulting in the formation of unstable fatty acid radicals, which can cause cell damage (44). Moreover, in the presence of $\mathrm{H}_{2} \mathrm{O}_{2}$, $\mathrm{NO}$ can be converted into peroxynitrite, a potent oxidant that reacts with unsaturated fatty acids within liposomes to initiate lipid peroxidation chain reactions and eliminate lipid-soluble antioxidants $(44,46,47)$. Therefore, both exogenous chemicals $\mathrm{CoCl}_{2}$ and SNP induce oxidative stress, and their cytotoxic effects on viable cells are similar in terms of the overall reduction in metabolites, as observed in the present study.

The oxidative stress cell model established using PE serum did not share a similar metabolite profile with any of the other four cell models. In the PE model, the extracellular excretion of $\omega-6$ unsaturated fatty acids (bihomo- $\gamma$-linoleate and arachidonate) and $\omega-3$ unsaturated fatty acids [eicosapentaenoate (EPA) and docosahexaenoate (DHA)] was higher. These fatty acids are involved in vasodilation, as well as having anti-inflammatory and antioxidant properties. For instance, bihomo- $\gamma$-linoleate is desaturated to arachidonate, which acts as the precursor for the production of prostaglandins (48). EPA serves as another precursor for the biosynthesis of prostaglandin and anti-inflammatory leukotrienes-5 (49). Both EPA and DHA, via the cyclooxygenase and lipoxygenase pathways, have potent anti-inflammatory and pro-resolving effects, as well as the ability to suppress the expression of pro-inflammatory cytokines such as tumor necrosis factor- $\alpha$, interleukin- 6 and plasminogen activator inhibitor-1 $(50,51)$. EPA and DHA also facilitate circulating glutathione peroxidase and superoxide dismutase, and they exhibit vasodilating properties via the inhibition of $\mathrm{Na} / \mathrm{Ca}^{2+}$ exchange and $\alpha 1$-adrenoceptor activity (52). As these $\omega$-unsaturated fatty acids are involved in the protective cellular mechanisms against inflammation and oxidative stress, it is hypothesized that PE serum, rather than being a potent oxidative stress inducer like the other models, initi- ates protective physiological responses in HTR8/SVneo cells during the early stages of disease progression. Therefore, the suitability of PE serum to study oxidative stress underlying PE pathogenesis may need to be reconsidered.

In the present study, it was hypothesized that while HTR8/SVneo cells are capable of maintaining their intracellular metabolic homeostasis under $1 \% \mathrm{O}_{2}$ hypoxia, they attempt to modify their external environment via extracellular secretion. In the hypoxia group, it was observed that only two intracellular metabolites were reduced, meanwhile ten extracellular metabolites, in particular fatty acids, were secreted into the spent media. HTR8/SVneo cells are an extravillous trophoblast cell. Trophoblast cells experience a physiological hypoxic environment $\left(3 \% \mathrm{O}_{2}\right)$ 8-10 weeks into pregnancy $(53,54)$, so it is unsurprising that these cells exhibited hypoxic tolerance in $1 \% \mathrm{O}_{2}$ for $24 \mathrm{~h}$, with only minor intracellular metabolic disturbances observed. In addition to withstanding hypoxic conditions, trophoblast cells can also increase the secretion of angiogenic factors in order to promote new blood vessel formation to increase $\mathrm{O}_{2}$ supply (55). In the present study, cells in the hypoxia group showed increased excretion of conjugated linoleic acid; this is a polyunsaturated fatty acid that has been reported to stimulate the angiogenesis of placental trophoblast cells in the first trimester (56). In addition, conjugated linoleic acid suppresses ROS production via the upregulation of peroxisome proliferator-activated receptor $\gamma$ expression $(57,58)$.

The present study had certain limitations that should be considered when designing future studies. Firstly, it would be useful to study primary cell lines isolated directly from human placenta in order to investigate metabolic changes under various oxidative perturbations. Secondly, genomic and proteomic data should be investigated to further validate the metabolomic findings and support conclusions from the present study.

In conclusion, the present study showed the differences between the intracellular and extracellular metabolite profiles of five different oxidative stress cell models commonly used to study pregnancy complications. The findings suggested that there is a need for the standardization of cell models used for oxidative stress research in order to avoid contradictory findings, particularly in the discipline of perinatal research.

\section{Acknowledgements}

The authors would like to thank Dr Charles Graham at Queen's University, Canada, for providing HTR8/SVneo cells.

\section{Funding}

The present study was supported by The National Natural Science Foundation of China (grant nos. 81571453, $81771607,81871185,81701477$ and 81471473). The 111 Project [grant no. Yuwaizhuan (2016)32], The National Key Research and Development Program of Reproductive Health \& Major Birth Defects Control and Prevention (grant no. 2016YFC1000407), Chongqing Health Commission (grant nos. 2017ZDXM008 and 2018ZDXM024), and Chongqing Science \& Technology Commission (grant no. cstc2017jcyjBX0062). 


\section{Availability of data and materials}

The datasets used and analyzed during the current study are available from the corresponding author on reasonable request.

\section{Authors' contributions}

JC performed the experiments. XZ designed the experiment. $\mathrm{JC}$ and TLH conducted the statistical analysis of the data and drafted the manuscript. HZ, YS and PB conceived the study, participated in its design and coordination, and helped to draft the manuscript.

\section{Ethics approval and consent to participate}

All participants at enrollment signed written informed consent and this study was approved by The Ethics Committee of Chongqing Medical University (policy no. 2014034).

\section{Patient consent for publication}

Not applicable.

\section{Competing interests}

The authors declare that they have no competing interests.

\section{References}

1. Aouache R, Biquard L, Vaiman D and Miralles F: Oxidative stress in preeclampsia and placental diseases. Int J Mol Sci 19: pii: E1496, 2018

2. Espinosa-Diez C, Miguel V, Mennerich D, Kietzmann T, Sánchez-Pérez P, Cadenas S and Lamas S: Antioxidant responses and cellular adjustments to oxidative stress. Redox Biol 6: 183-197, 2015.

3. Burton GJ, Woods AW, Jauniaux E and Kingdom JC: Rheological and physiological consequences of conversion of the maternal spiral arteries for uteroplacental blood flow during human pregnancy. Placenta 30: 473-482, 2009.

4. Kalyanaraman B: Teaching the basics of redox biology to medical and graduate students: Oxidants, antioxidants and disease mechanisms. Redox Biol 1: 244-257, 2013.

5. Mannaerts D, Faes E, Cos P, Briedé JJ, Gyselaers W, Cornette J, Gorbanev Y, Bogaerts A, Spaanderman M, Van Craenenbroeck E and Jacquemyn Y: Oxidative stress in healthy pregnancy and preeclampsia is linked to chronic inflammation, iron status and vascular function. PLoS One 13: e0202919, 2018.

6. Yang X, Guo L, Li H, Chen X and Tong X: Analysis of the original causes of placental oxidative stress in normal pregnancy and pre-eclampsia: A hypothesis. J Matern Fetal Neonatal Med 25: 884-888, 2012

7. Burton GJ and Jauniaux E: Placental oxidative stress: From miscarriage to preeclampsia. J Soc Gynecol Investig 11: 342-352, 2004.

8. Mert I, Oruc AS, Yuksel S, Cakar ES, Buyukkagnici U, Karaer A and Danisman N: Role of oxidative stress in preeclampsia and intrauterine growth restriction. J Obstet Gynaecol Res 38: 658-664, 2012

9. Wu F, Tian FJ, Lin Y and Xu WM: Oxidative stress: Placenta function and dysfunction. Am J Reprod Immunol 76: 258-271, 2016

10. De Paepe C, Krivega M, Cauffman G, Geens $M$ and Van de Velde H: Totipotency and lineage segregation in the human embryo. Mol Hum Reprod 20: 599-618, 2014.

11. Alahari S, Post M and Caniggia I: Jumonji domain containing protein 6: A novel oxygen sensor in the human placenta. Endocrinology 156: 3012-3025, 2015.

12. Baker PN, Davidge ST, Barankiewicz J and Roberts JM: Plasma of preeclamptic women stimulates and then inhibits endothelial prostacyclin. Hypertension 27: 56-61, 1996.
13. He G, Xu W, Chen Y, Liu X and Xi M: Abnormal apoptosis of trophoblastic cells is related to the up-regulation of CYP11A gene in placenta of preeclampsia patients. PLoS One 8: e59609, 2013.

14. Luo X, Yao ZW, Qi HB, Liu DD, Chen GQ, Huang S and Li QS: Gadd45a as an upstream signaling molecule of p38 MAPK triggers oxidative stress-induced sFlt-1 and sEng upregulation in preeclampsia. Cell Tissue Res 344: 551-565, 2011.

15. Yuan Y, Hilliard G, Ferguson T and Millhorn DE: Cobalt inhibits the interaction between hypoxia-inducible factor-alpha and von Hippel-Lindau protein by direct binding to hypoxia-inducible factor-alpha. J Biol Chem 278: 15911-15916, 2003.

16. Luo R, Wang Y, Xu P, Cao G, Zhao Y, Shao X, Li YX, Chang C, Peng $C$ and Wang YL: Hypoxia-inducible miR-210 contributes to preeclampsia via targeting thrombospondin type I domain containing 7A. Sci Rep 6: 19588, 2016.

17. Zou Y, Zuo Q, Huang S, Yu X, Jiang Z, Zou S, Fan M and Sun L: Resveratrol inhibits trophoblast apoptosis through oxidative stress in preeclampsia-model rats. Molecules 19: 20570-20579, 2014.

18. Saito $S$ and Nakashima A: A review of the mechanism for poor placentation in early-onset preeclampsia: The role of autophagy in trophoblast invasion and vascular remodeling. J Reprod Immunol 101-102: 80-88, 2014.

19. Covarrubias AE, Lecarpentier E, Lo A, Salahuddin S, Gray KJ, Karumanchi SA and Zsengellér ZK: AP39, a modulator of mitochondrial bioenergetics, reduces antiangiogenic response and oxidative stress in hypoxia-exposed trophoblasts: Relevance for preeclampsia pathogenesis. Am J Pathol 189: 104-114, 2019.

20. Yang Z, Bai B, Luo X, Xiao X, Liu X, Ding Y, Zhang H, Gao L, Li J and Qi H: Downregulated Kruppel-like factor 8 is involved in decreased trophoblast invasion under hypoxia-reoxygenation conditions. Reprod Sci 21: 72-81, 2014.

21. Zhuang B, Luo X, Rao H, Li Q, Shan N, Liu X and Qi H: Oxidative stress-induced $\mathrm{C} / \mathrm{EBP} \beta$ inhibits $\beta$-catenin signaling molecule involving in the pathology of preeclampsia. Placenta 36: 839-846, 2015.

22. Nangaku M and Eckardt KU: Hypoxia and the HIF system in kidney disease. J Mol Med (Berl) 85: 1325-1330, 2007.

23. Myatt L and Cui X: Oxidative stress in the placenta. Histochem Cell Biol 122: 369-382, 2004

24. Silva JP, Proenca F and Coutinho OP: Protective role of new nitrogen compounds on ROS/RNS-mediated damage to PC12 cells. Free Radic Res 42: 57-69, 2008.

25. Williamson RD, McCarthy C, McCarthy FP and Kenny LC: Oxidative stress in pre-eclampsia; Have we been looking in the wrong place? Pregnancy Hypertension 8: 1-5, 2017.

26. Melland-Smith M, Ermini L, Chauvin S, Craig-Barnes H, Tagliaferro A, Todros T, Post M and Caniggia I: Disruption of sphingolipid metabolism augments ceramide-induced autophagy in preeclampsia. Autophagy 11: 653-669, 2015.

27. Sugawara J, Suh DS, Faessen GH, Suen LF, Shibata T, Kaper F, Giaccia AJ and Giudice LC: Regulation of insulin-like growth factor-binding protein-1 by nitric oxide under hypoxic conditions. J Clin Endocrinol Metab 85: 2714-2721, 2000.

28. English FA, McCarthy FP, McSweeney CL, Quon AL, Morton JS, Sawamura T, Davidge ST and Kenny LC: Inhibition of lectin-like oxidized low-density lipoprotein-1 receptor protects against plasma-mediated vascular dysfunction associated with pre-eclampsia. Am J Hypertens 26: 279-286, 2013.

29. McCarthy $\mathrm{C}$ and Kenny LC: Therapeutically targeting mitochondrial redox signalling alleviates endothelial dysfunction in preeclampsia. Sci Rep 6: 32683, 2016.

30. Sokolov DI, Ovchinnikova OM, Korenkov DA, Viknyanschuk AN, Benken KA, Onokhin KV and Selkov SA: Influence of peripheral blood microparticles of pregnant women with preeclampsia on the phenotype of monocytes. Transl Res 170: 112-123, 2016.

31. Xu Q, Du F, Zhang Y, Teng Y, Tao M, Chen AF and Jiang R: Preeclampsia serum induces human glomerular vascular endothelial cell hyperpermeability via the HMGB1-Caveolin-1 pathway. J Reprod Immunol 129: 1-8, 2018.

32. Roberts JM and Hubel CA: The two stage model of preeclampsia: Variations on the theme. Placenta 30 (Suppl A): S32-S37, 2009.

33. Tamaru S, Kajihara T, Mizuno Y, Takano N, Tochigi H, Sato T and Ishihara O: Heparin prevents oxidative stress-induced apoptosis in human decidualized endometrial stromal cells. Med Mol Morphol: Mar 16, 2019 (Epub ahead of print). doi: 10.1007/s00795-019-00220-x.

34. Grosser N, Abate A, Oberle S, Vreman HJ, Dennery PA, Becker JC, Pohle T, Seidman DS and Schröder H: Heme oxygenase-1 induction may explain the antioxidant profile of aspirin. Biochem Biophys Res Commun 308: 956-960, 2003. 
35. Huang S, Mo TT, Norris T, Sun S, Zhang T, Han TL, Rowan A, Xia YY, Zhang H, Qi HB and Baker PN: The CLIMB (Complex Lipids In Mothers and Babies) study: Protocol for a multicentre, three-group, parallel randomised controlled trial to investigate the effect of supplementation of complex lipids in pregnancy, on maternal ganglioside status and subsequent cognitive outcomes in the offspring. BMJ Open 7: e016637, 2017.

36. Graham CH,Hawley TS, Hawley RG, MacDougall JR, Kerbel RS, Khoo N and Lala PK: Establishment and characterization of first trimester human trophoblast cells with extended lifespan. Exp Cell Res 206: 204-211, 1993.

37. Smart KF, Aggio RBM, Van Houtte JR and Villas-Bôas SG: Analytical platform for metabolome analysis of microbial cells using methyl chloroformate derivatization followed by gas chromatography-mass spectrometry. Nat Protoc 5: 1709-1729, 2010.

38. Smith CA, Want EJ, O'Maille G, Abagyan R and Siuzdak G: XCMS: Processing mass spectrometry data for metabolite profiling using nonlinear peak alignment, matching, and identification. Anal Chem 78: 779-787, 2006.

39. Xia J, Sinelnikov IV, Han B and Wishart DS: MetaboAnalyst 3.0-making metabolomics more meaningful. Nucleic Acids Res 43: W251-W257, 2015.

40. Wickham H: Ggplot2: Elegant graphics for data analysis. Springer, New York, 2009.

41. Ferguson BS, Rogatzki MJ, Goodwin ML, Kane DA, Rightmire Z and Gladden LB: Lactate metabolism: Historical context, prior misinterpretations, and current understanding. Eur J Appl Physiol 118: 691-728, 2018.

42. Hess ML and Manson NH: Molecular oxygen: Friend and foe The role of the oxygen free radical system in the calcium paradox the oxygen paradox and ischemia/reperfusion injury. J Mol Cell Cardiol 16: 969-985, 1984

43. Liu J, Litt L, Segal MR, Kelly MJ, Pelton JG and Kim M: Metabolomics of oxidative stress in recent studies of endogenous and exogenously administered intermediate metabolites. Int J Mol Sci 12: 6469-6501, 2011.

44. Hogg N and Kalyanaraman B: Nitric oxide and lipid peroxidation. Biochim Biophys Acta 1411: 378-384, 1999.

45. Guan D, Su Y, Li Y, Wu C, Meng Y, Peng X and Cui Y: Tetramethylpyrazine inhibits CoCl2-induced neurotoxicity through enhancement of $\mathrm{Nrf} 2 / \mathrm{GCLc} / \mathrm{GSH}$ and suppression of HIF1a/NOX2/ROS pathways. J Neurochem 134: 551-565, 2015.

46. Chun HS and Low WC: Ursodeoxycholic acid suppresses mitochondria-dependent programmed cell death induced by sodium nitroprusside in SH-SY5Y cells. Toxicology 292: 105-112, 2012.
47. Dominiak A, Wilkaniec A, Wroczynski P, Jeśsko $\mathrm{H}$ and Adamczyk A: Protective effects of selol against sodium nitroprusside-induced cell death and oxidative stress in PC12 Cells. Neurochem Res 41: 3215-3226, 2016.

48. Innes JK and Calder PC: Omega- 6 fatty acids and inflammation. Prostaglandins Leukot Essent Fatty Acids 132: 41-48, 2018.

49. Pollard JK and Mitchell MD: Intrauterine infection and the effects of inflammatory mediators on prostaglandin production by myometrial cells from pregnant women. Am J Obstet Gynecol 174: 682-686, 1996.

50. Geleijnse JM, Giltay EJ, Grobbee DE, Donders AR and Kok FJ: Blood pressure response to fish oil supplementation: Metaregression analysis of randomized trials. J Hypertens 20: 1493-1499, 2002.

51. Poniedzialek-Czajkowska E, Mierzynski R, Kimber-Trojnar Z, Leszczynska-Gorzelak B and Oleszczuk J: Polyunsaturated fatty acids in pregnancy and metabolic syndrome: A review. Curr Pharm Biotechnol 15: 84-99, 2014.

52. Hallaq H, Smith TW and Leaf A: Modulation of dihydropyridine-sensitive calcium channels in heart cells by fish oil fatty acids. Proc Natl Acad Sci USA 89: 1760-1764, 1992.

53. Bilodeau JF: Review: Maternal and placental antioxidant response to preeclampsia-impact on vasoactive eicosanoids. Placenta 35 (Suppl): S32-S38, 2014.

54. Zhang Z, Li P, Wang Y and Yan H: Hypoxiainduced expression of CXCR4 favors trophoblast cell migration and invasion via the activation of HIF1a. Int J Mol Med 42: 1508-1516, 2018.

55. Xu C, Li X, Guo P and Wang J: Hypoxia-Induced Activation of JAK/STAT3 signaling pathway promotes trophoblast cell viability and angiogenesis in preeclampsia. Med Sci Monit 23: 4909-4917, 2017.

56. Basak S, Das MK and Duttaroy AK: Fatty acid-induced angiogenesis in first trimester placental trophoblast cells: Possible roles of cellular fatty acid-binding proteins. Life Sci 93: 755-762, 2013.

57. Dipasquale D, Basiricò L, Morera P, Primi R, Tröscher A and Bernabucci U: Anti-inflammatory effects of conjugated linoleic acid isomers and essential fatty acids in bovine mammary epithelial cells. Animal 12: 2108-2114, 2018.

58. Li K, Sinclair AJ, Zhao F and Li D: Uncommon fatty acids and cardiometabolic health. Nutrients 10: 1559, 2018 